\title{
REVIEW
}

\section{Rice Bran Oil: A Versatile Source for Edible and Industrial Applications}

\author{
Yogita P. Pal and Amit P. Pratap* \\ Department of Oils, Oleochemicals and Surfactants Technology, Institute of Chemical Technology (University under Section 3 of UGC Act 1956; \\ Formerly UDCT/ UICT), Nathalal Parekh Road, Matunga (East), Mumbai - 400019 INDIA
}

\begin{abstract}
Rice bran oil (RBO) is healthy gift generously given by nature to mankind. RBO is obtained from rice husk, a byproduct of rice milling industry and is gaining lot of importance as cooking oil due to presence of important micronutrient, gamma oryzanol. Its high smoke point is beneficial for its use for frying and deep frying of food stuff. It is popular because of balanced fatty acid profile (most ideal ratio of saturated, monounsaturated and polyunsaturated fatty acids), antioxidant capacity, and cholesterollowering abilities. Rice bran wax which is secondary by-product obtained as tank settling from RBO is used as a substitute for carnauba wax in cosmetics, confectionery, shoe creams etc. It can be also used as a source for fatty acid and fatty alcohol. The article is intended to highlight for the importance of RBO and its applications.
\end{abstract}

Key words: gamma oryzanol, rice bran, antioxidant, rice bran wax

\section{Introduction}

Dietary fat is a crucial factor in the regulation of plasma cholesterol level $^{1)}$. Dietary fat consumption is correlated with Coronary Heart Diseases (CHD) and stroke mortality. A diet rich in food of plant origin can significantly retard the development of $\mathrm{CHD}^{2)}$. The vegetable oils rich in polyunsaturated fatty acid, mainly linoleic acid (18:2), supports hypocholestrolemic effect ${ }^{1)}$. Rice bran, a co-product of milled rice, and its oil have cardiovascular health benefits. Human consumption of rice bran has been limited, primarily because of the rapid onset of rancidity in rice bran, but methods to stabilize rice bran and to extract its oil have been developed. Interest in rice bran grew from the determination that the inclusion of oat bran in the diet lowers the serum cholesterols ${ }^{3)}$.

Rice Bran Oil (RBO) typically contains $22 \%$ of saturated fatty acid (SFA), $43 \%$ of monounsaturated fatty acid (MUFA) and 35\% polyunsaturated fatty acid(PUFA). This composition is extremely close to the American Heart Association (AHA) and World Health Organization (WHO) recommendations on edible oils ${ }^{6)}$. Research showed the deleterious effects of SFA on blood total cholesterol concentrations, and the fact that RBO lowers blood cholesterol is contrary to these findings. Now research suggests that RBO's cholesterol lowering properties are explained by its unsaponifiable components more than by its fatty acid composition ${ }^{3)}$. Table 1 shows the fatty acid composition of RBO in comparison with other vegetable oils.

The amount of unsaponifiable compounds present in commercial RBO is dependent on refining processes ${ }^{4}$. The most notable unsaponifiable compounds present in RBO are $\gamma$ - oryzanol (a ferulate ester of triterpene alcohols), tocopherols and tocotrienols having excellent cholesterol lowering potential. Also RBO is rich source of plants sterols i.e. phytosterols which again results in lowering of blood cholesterol level. Thus there are efforts being taken to develop RBO retaining its unsaponifiable components, while minimizing levels of problematic free fatty acids ${ }^{5)}$. Table 2 shows the cholesterol lowering activity of RBO in comparison with other vegetable oils.

Although RBO is touted as one of the healthiest oils in the world, but still not reaching its full production potential. The major RBO producers - India, Japan, China, Thailand and Vietnam are taking efforts for the production and promotion of RBO by creating awareness among the society regarding the health benefits which can be achieved by the consumption of RBO. India, the leading $\mathrm{RBO}$ producer, is a good example of how to improve con-

\footnotetext{
*Correspondence to: Amit P. Pratap, Department of Oils, Oleochemicals and Surfactants Technology, Institute of Chemical Technology (University under Section 3 of UGC Act 1956; Formerly UDCT/ UICT), Nathalal Parekh Road, Matunga (East), Mumbai - 400019 INDIA E-mail: amitpratap2001@gmail.com, ap.pratap@ ictmumbai.edu.in Accepted April 3, 2017 (received for review March 6, 2017) Journal of Oleo Science ISSN 1345-8957 print / ISSN 1347-3352 online http://www.jstage.jst.go.jp/browse/jos/ http://mc.manusriptcentral.com/jjocs
} 
Table 1 Fatty acid profits of RBO and other vegetable oils.

\begin{tabular}{cccc}
\hline Oil & \multicolumn{3}{c}{ Fatty Acid \% Wt } \\
\hline Sesame & 13 & 41 & 46 \\
Mustard/Rapeseed & 3 & 68 & 29 \\
Cottonseed & 26 & 19 & 55 \\
Sunflower & 12 & 19 & 69 \\
Safflower & 9 & 13 & 78 \\
Soybean & 15 & 24 & 61 \\
Palm & 50 & 40 & 10 \\
Olive & 16 & 73 & 11 \\
Canola & 6 & 62 & 32 \\
Corn & 13 & 28 & 59 \\
Coconut & 92 & 6 & 2 \\
Palm kernel & 86 & 12 & 2 \\
Groundnut & 22 & 45 & 33 \\
Rice Bran & 22 & 43 & 35 \\
Recommended & $27-33 \%$ & $33-40 \%$ & $27-33 \%$ \\
\hline
\end{tabular}

Table 2 Cholesterol lowering activity of RBO in comparison with other vegetable oils.

\begin{tabular}{ccc}
\hline Edible Oil & Linoleic Acid \% & Cholesterol Level \\
\hline Safflower & 77.1 & -16 \\
Sunflower & 61.4 & -12 \\
Cottonseed & 58.0 & 0 \\
Soybean & 50.2 & +3 \\
Sesame & 45.9 & +2 \\
Corn & 43.0 & -15 \\
Rice Barn & 36.0 & -17 \\
Groundnut & 35.0 & +5 \\
\hline
\end{tabular}

sumer acceptance and awareness of the oil. Although the nation has produced RBO for the decades, it has not received much attention until the last few years. But with the launch of Fortune Rice Bran Health in 2012, the first brand to promote $100 \% \mathrm{RBO}$, and subsequent promotions by other brands, rice bran oil has been in the limelight ${ }^{7}$.

\section{Rice bran oil (RBO)}

Rice bran is the outer brown layer of the rice grain. The basic components of a paddy grain are fiber, lipids, amino acids as well as a variety of vitamins and minerals. This nutritionally rich bran is obtained as a by-product of the rice
Table 3 Chemical composition of RBO.

\begin{tabular}{cc}
\hline Composition & $\%$ \\
\hline Triacylglycerols & 80.5 \\
Free Fatty acids & 6.8 \\
Diacylglycerols & 4.8 \\
Monoacylglycerols & 1.7 \\
Oryzanol & 2.0 \\
Phosphatides & 1.3 \\
Wax & 2.9 \\
\hline
\end{tabular}

milling process. The oil extracted from this bran is called rice bran oil.

Traditionally, in many of the Asian countries, including Indonesia and India, rice bran is largely been fed to cattle. However, Japan has considered rice bran to be a valuable resource since ages and extracted oil out of it. In fact, RBO is more popularly known as 'Heart Oil' in Japan. Now, it is emerging as a popular cooking oil in several Asian countries, especially for deep and shallow frying applications ${ }^{8)}$. Although whole rice bran in itself does not have anti-cholesterol properties, its oil offers nutritional benefits. Table 3 shows the chemical composition of RBO.

RBO has a characteristic nutty, earthly flavour like peanut oil. The fatty acid composition of rice bran oil is most similar to peanut or ground nut oil (Table 1 $)^{9)}$. Palmitic, oleic, and linoleic acids make up more than $90 \%$ of the fatty acids present. The major molecular species of tria- 
Table 4 Micro-nutrient profile of RBO.

\begin{tabular}{|c|c|c|}
\hline Micro-nutrient & Amount \% & Advantage \\
\hline Tocopherol & $0.02-0.08$ & $\begin{array}{l}\text { Antioxidant, Free radical scavenger, Reduce } \\
\text { risk of cardio vascular diseases, arthritis, } \\
\text { cancer and cataract, Anti-tumor activities. }\end{array}$ \\
\hline Tocotrienol & $0.025-0.17$ & $\begin{array}{l}\text { Cholesterol reduction, Reversing } \\
\text { Atheroscelerosis, Anti-cancer (breast, liver) } \\
\text { tumor suppression, Antioxidant }\end{array}$ \\
\hline Oryzanol & $1.2-1.7$ & $\begin{array}{l}\text { Increase good (HDL) cholesterol and decrease } \\
\text { bad (LDL) cholesterol, Treats nerve imbalance } \\
\text { \& Menopause disorder, Anti-aging effects, } \\
\text { Antidandruff and anti-itching agent. }\end{array}$ \\
\hline Squalene & $0.3-0.4$ & Antioxidant \\
\hline
\end{tabular}

cylglycerols are linoleoyl-dioleoylglycerol, palmitoyl-dilinoleoylglycerol, oleoyl-dilinoleoylglycerol and trioleoylglycerol.

\subsection{Nutritional content in RBO}

The initial interest in RBO resulted from work with the stabilized rice bran. Rice bran was shown to have same serum cholesterol reduction activity as oat bran in hamster trials. Two clinical studies showed rice bran reduced serum low-density lipoprotein (LDL) cholesterol in humans. Defatted bran was less effective in lowering cholesterol than full fat bran. The cholesterol-lowering activity was concentrated in the unsaponifiable fraction of RBO. Oryzanol was found to contribute to the hypocholesterolemic activity of $\mathrm{RBO}$ in rats and primates. A clinical study with $3.1 \mathrm{~g} /$ day of RBO unsaponifiables over a 12-month period resulted in a $14.1 \%$ reduction in total cholesterol and a $20.5 \%$ reduction on LDL-cholesterol. HDL cholesterol rose, while triacylglycerols decreased significantly. Tocotrienols, also present in RBO, have been reported to reduce serum cholesterol $^{9)}$. Table 4 shows different micronutrient present in $\mathrm{RBO}$ with their health benefits.

\subsection{RBO production (Potential)}

World rice production is greater than 500 million metric tons. Rice oil production is estimated at 740.2 thousand metric tons (Table 5). India, China, and Japan are the leading producers. More than half of rice is processed in small rice mills. This leaves approximately 20-25 million metric tons of bran available for oil production. The RBO potential is, then, 3-4 million metric tons. In the United States, most bran is also produced in small rice mills scattered in rice production areas with insufficient bran production to justify oil extraction. Production estimates are far less than 80 thousand metric tons and is nearly 18 thousand metric tons ${ }^{9)}$.
Table 5 Production of RBO (2015-2016).

\begin{tabular}{cc}
\hline Country & Thousand Metric Tons \\
\hline Bangladesh & 1.5 \\
Brazil & 1.5 \\
Cambodia & 4.6 \\
China & 90.0 \\
India & 427.7 \\
Indonesia & 0.15 \\
Japan & 65.0 \\
Korea & 11.7 \\
Republic of Korea & 9.2 \\
Laos & 2.6 \\
Burma & 17.6 \\
Nepal & 7.6 \\
Pakistan & 3.7 \\
Sri Lanka & 5.5 \\
Thailand & 7.8 \\
United States & 18 \\
Vietnam & 7.6 \\
Total & 740.2 \\
\hline
\end{tabular}

\section{RBO Economic aspects in India}

India being the major leading $\mathrm{RBO}$ producer in the world, it accumulates large revenue by exporting RBO to other countries like U.S, gulf countries etc. RBO exported during the period April 2015 to April 2016 was nearly 24 thousand metric tons having INR value 22.25 crores. The total revenue collected from the export of oil by the country during the same period was nearly 250 crore. Thus RBO serves the $10 \%$ of total amount obtained from the export of oils, which is very remarkable in increasing India's GDP growth. States leading in RBO production in India are Andhra Pradesh, Tamil Nadu, Punjab, Karnataka and Uttar 
Table 6 Production of RBO from different states of India (2015-2016).

\begin{tabular}{ccccc}
\hline States & $\begin{array}{c}\text { Processed } \\
\text { (million tons) }\end{array}$ & $\begin{array}{c}\text { Edible } \\
\text { (million tons) }\end{array}$ & $\begin{array}{c}\text { Industrial } \\
\text { (million tons) }\end{array}$ & $\begin{array}{c}\text { Total } \\
\text { (million tons) }\end{array}$ \\
\hline Andhra Pradesh & 427831 & 74016 & 1183 & 75199 \\
Assam & 5323 & - & 611 & 611 \\
Chhattisgarh & 202559 & 40833 & - & 40833 \\
Haryana & 98350 & 10595 & 5229 & 15824 \\
Karnataka & 308898 & 49893 & 719 & 50612 \\
Maharashtra & 3916 & 617 & - & 617 \\
Orissa & 158369 & 28921 & 346 & 29267 \\
Punjab & 346137 & 46367 & 3282 & 49649 \\
Tamil Nadu & 365743 & 41380 & 8623 & 50003 \\
Uttar Pradesh & 287458 & 22610 & 18467 & 41077 \\
Uttaranchal & 43806 & - & 6019 & 6019 \\
West Bengal & 191828 & 26454 & 2211 & 28665 \\
Total & 2440218 & 341686 & 46690 & 388376 \\
\hline
\end{tabular}

Pradesh. There are also other states which produces the $\mathrm{RBO}$ but the production has not yet reached the full potential. Table 6 shows the states producing the RBO and production data during the period April 2015- 2016 ${ }^{6}$.

\section{Rice Bran Wax (RBW)}

Waxes are not found in all types of edible oils but for certain oils those derived from rice bran, sunflower, corn, it becomes necessary to perform dewaxing to decrease the oil turbidity and to improve its appearance ${ }^{22)}$. Wax is the most important among by-product separated from oil. It is obtained by washing with acetone, destruction of the phosphatides through hydrolysis or saponification, and subsequent purification by fractionation from isopropanol solution. Another way used is hydration of the tank settlings, followed by separation of the aqueous and oil phases, and fractionation of the oil phase from isopropanol solution. The hard wax is almost black in color in the liquid state and could not be bleached readily with activated clay or carbon. The wax is bleached readily by hydrogen peroxide and by chromium trioxide in the presence of sulfuric acid solution, or by combinations of these reagents. Practically white waxes could be produced with 0.5 part of $29 \%$ hydrogen peroxide and 1 part of chromium trioxide per 1 part of wax. Wax was the only constituent of RBO that remarkably increases the viscosity ( $81.5 \%$ ) of oil. Monoacylglycerols synergistically raised the viscosity of the oil (by $114.2 \%)$ and lowered the rate of wax settling. Although a reduction in the viscosity of the oil significantly decreased the refining loss, the minimum loss attained was still $20 \%$ more than the theoretically predicted value. Therefore, monoacylglycerols must be removed before dewaxing; thereafter, oryzanol and phospholipids have to be removed $^{10-12)}$.

Hard and soft waxes are separated from the tank settling of crude RBO by solvent extraction. The presence of an aromatic moiety is indicated in the infra red spectrum. Melting points of the hard wax and the soft wax are $80^{\circ} \mathrm{C}$ and $74^{\circ} \mathrm{C}$, respectively, and that the hard wax was mainly composed of wax esters of saturated fatty alcohols of C24, C26 and C30 and saturated fatty acids of C22, C24 and C26, and $n$-alkanes of C29 and C31. The soft wax was mainly composed of wax esters of saturated fatty alcohols of C24 and C30 and saturated fatty acids of C16 and C26, and $n$-alkanes of C21 and C29. Fatty acid steryl esters (FASE) and wax esters (WE) of RBO have potential applications in cosmetic, nutraceutical, and pharmaceutical formulations ${ }^{13-15)}$.

The major impurity in the defatted wax was the dark brown resinous matter that can be removed by bleaching with sodium borohydride in isopropanol to yield pale yellow, odorless wax with purity higher than $99 \%$ and with melting point of $80-83^{\circ} \mathrm{C}$. The resinous matter is a mixture of aliphatic aldehydes, fatty alcohols, and fatty acids ${ }^{16)}$.

A comparative nutritive study was made to show that the extent of purification markedly influences the nutritive characteristics of RBO. Digestibility of RBO (when degummed, decidified, bleached and deodorized) was found to be $93.8 \%$ for rats; whereas it was $94.8 \%$ for extremely pure RBO (including dewaxing step). RBO without deodorization, but purified by other treatments, showed a $96.2 \%$ of digestibility ${ }^{17)}$. 


\section{$5 \gamma$-Oryzanol in RBO}

The effects of minor components in crude RBO including FFAs, RBW, $\gamma$-oryzanol, and long-chain fatty alcohols (LCFA), on alkali refining losses were determined. Oryzanol is an important value-added co-product of the rice and rice bran-refining processes. The beneficial effects of oryzanol on human health have generated global interest in developing facile methods for its separation from rice bran oil soapstock, a by-product of the chemical refining of RBO. The problems encountered and the ways to solve them during oryzanol extraction, such as prior processing and compositional variation in soapstock, resistance to mass transfer, moisture content and the presence of surface active components, which cause emulsion formation, should be examined. Engineering inputs required for solving problems such as saponification, increasing mass transfer area, and drying methods also should be carefully designed $^{18,19)}$. The TLC-densitometric and TLC-image analysis methods are useful for quantitative determination of $\gamma$-oryzanol in cold presses $\mathrm{RBO}^{27)}$. The residue of fatty acids distillation from rice bran oil soapstock (RFADRBOS) is a by-product from RBO industry that also contains a large amount of oryzanol ${ }^{28)}$.

\section{Rice bran protein}

The increasing demand for rice bran and RBO as healthy functional food ingredients has led to the emergence of defatted rice bran as a potential by-product such as rice bran meal after the extraction of oil from rice $b r a n^{26)}$. Rice bran protein $(\mathrm{RBP})$ was prepared by alkali extraction and isoelectric precipitation from defatted rice bran. The true digestibility of $\operatorname{RBP}(94.8 \%)$ was higher than that of REP $(90.8 \%), \operatorname{ISP}(91.7 \%)$ and WPI $(92.8 \%)$ and the same as that of casein ${ }^{20)}$.

\section{Biodiesel based on RBO}

Human history for energy uses started with utilization of sun for light and heat. Later fossil fuels started serving human needs with great potential energy. With advent in modern technologies the utilization of energy is increasing rapidly and fossil fuel is diminishing at a very fast rate. So it is the right time to invent a newer source of energy to meet the scarcity for energy ${ }^{24)}$. Diesel engine emits higher NOx emissions than gasoline engines due to local high concentration of oxygen molecules ${ }^{25)}$. Biodiesel is receiving increased attention as an alternative, non-toxic, biodegradable, and renewable diesel fuel. RBO offers significant potential as an alternative low-cost feedstock for biodiesel production. Rice bran, a low valued co-product of rice milling, contains 15-23\% RBO. The effect of temperature, moisture and storage time on FFA content of RBO was studied for the development of efficient biodiesel ${ }^{21)}$.

Loss of bioactive components in acid-catalyzed methanolysis of vegetable oil is inevitable. Increasing the amount of catalyst and molar ratio of methanol to oil can convert all FFAs and acylglycerols (AGs) into fatty acid methyl esters (FAMEs); however, loss of bioactive components also increases. Loss of bioactive components can be mitigated by the reaction under nitrogen atmosphere ${ }^{23)}$. Alumina impregnated with potassium iodide showed high catalytic activity in the transesterification of RBO with $5 \mathrm{wt} \%$ of catalyst and $95.2 \%$ yield $^{29)}$. Some studies also revealed the fermentative production of bio hydrogen using de oiled rice bran as renewable biomass ${ }^{30)}$.

\section{Perspective and Conclusions}

$\mathrm{RBO}$ is gaining popularity in Asia and other countries due to balanced fatty acid profile and $\gamma$-oryzanol, which is a natural antioxidant present in the crude oil. RBO is economically available as it is obtained from rice bran as a byproduct. Due to its economical cost it fetches a lot of industrial applications in soaps surfactants, fatty alcohols, cosmetics etc. It is speculated that after identifying RBO as one of the most potential source for food and industrial application across the globe, very soon the rice bran oil will also join the broad spectrum of applications similar to soybean, rapeseed etc.

\section{References}

1) Sugano, M.; Tsuji, E. Rice bran oil and cholesterol metabolism. J. Nutr. 127, 521S-524S (1997).

2) Qureshi, A.A.; Bradlow, B.A.; Salser, W.A.; Brace, L.D. Novel tocotrienols of rice bran modulate cardiovascular disease risk parameters of hypercholesterolemic humans. J. Nutr. Biochem. 8, 290-298(1997).

3) Most, M.; Tulley, R.; Morales S.; Lefevre, M.; Rice bran oil, not fiber, lowers cholesterol in humans. Am. J. Clin. Nutr. 81, 64-68(2005).

4) Orthoefer, F.; Rice bran oil: healthy lipid source. Food Technol. 50, 62-64(1996).

5) Berger, A.; Rein, D.; Schafer, A.; Monnad, I.; Gremaud, G; Lambelet, P.; Bertoli, C. Similar cholesterol-lowering properties of rice bran oil, with varied $\gamma$-oryzanol, in mildly hypercholesterolemic men. Eur. J. Nutr. 44, 163-173 (2005).

6) Mehta, B.V.; Mogal, Y.M.; Chakraborty, S.S. SEA HANDBOOK: Unique reference book on Indian vegetable oil industry \& trade. $10^{\text {th }}$ revised ed. $1151-1156$ (2014).

7) http://www.world-grain.com/articles/news_home/Fea- 
tures/2016/02/Healthiest_oil_has_growth_pote. asp $x ? \mathrm{ID}=$ \% 7B9C6074B5-8FA4-4BD5-8E21-A7FBE44E5D49\%7D\&cck=1

8) http://www.riceactive.com/?page_id=203

9) Ortheofer, F.; Rice Bran Oil, Bailey's Industrial Oil \& Fat Products. $6^{\text {th }}$ Ed. 2, 465-489 (2005).

10) Cousins, E.; Fore, S.; Janssen, H. Rice bran oil. VIII. Tank settlings from crude rice bran oil as a source of wax. J. Am. Oil. Chem. Soc. 30, 9-14(1953).

11) Ramakrishna, P.; Venkatesh, K.; Poornima, T. Effect of wax content on flow properties of rice bran oil. J. Am. Oil. Chem. Soc. 64, 859-861 (1987).

12) Gopala Krishna, A.; Influence of viscosity on wax settling and refining loss in rice bran oil. J. Am. Oil. Chem. Soc. 70, 895-898(1993).

13) Yoon, S.; Rhee, J. Composition of waxes from crude rice bran oil. J. Am. Oil. Chem. Soc. 59, 561-563 (1982).

14) Gunawan, S.; Vali, S.; Ju, Y. Purification and identification of rice bran oil fatty acid steryl and wax esters. $J$. Am. Oil. Chem. Soc. 83, 449-456 (2006).

15) Belavadi, V.; Bhowmick, D. An investigation of rice bran oil tank settling. J. Am. Oil. Chem. Soc. 65, 241245(1988).

16) Vali, S.; Ju, Y.H.; Kaimal, T. A process for the preparation of food-grade rice bran wax and the determination of its composition. J. Am. Oil. Chem. Soc. 82, 57-64 (2005).

17) Sarkar, S.; Bhattacharyya, D. Nutrition of rice bran oil in relation to its purification. J. Am. Oil. Chem. Soc. 68, 956-962 (1991).

18) Narayan, A.; Barhate, R.; Raghavarao, K. Extraction and purification of oryzanol from rice bran oil and rice bran oil soapstock. J. Am. Oil. Chem. Soc. 83, 663670 (2006).

19) Aryusuk, K.; Puengtham, J.; Lilitchan, S. Effects of crude rice bran oil components on alkali-refining loss. J. Am. Oil. Chem. Soc. 85, 475-479(2008).

20) Han, S.; Chee, K.; Cho, S. Nutritional quality of rice bran protein in comparison to animal and vegetable protein. Food Chem. 172, 766-769 (2015).

21) Siti, Z.; Lai, C.; Shaik, R.; Ju, Y. A two-step acid-catalyzed process for the production of biodiesel from rice bran oil. Bioresour. Technol. 96, 1889-1896 (2005).

22) Strieder, M.M.; Pinheiro, C.P.; Borba, V.S.; Pohndorf, R.S.; Cadaval Jr, T.R.S.; Pinto, L.A.A. Bleaching optimization and refinement of rice bran oil. Sep. Purif. Tech. 175, 72-78(2017).

23) Ju, Y.; Siti, Z. Effect of acid-catalyzed methanolysis on the bioactive components of rice bran oil. Taiwan Inst. Chem. Engine. 44, 924-928(2013).

24) Hasana, A.; Wakila, M.; Kafya, M. Prospect of rice bran for biodiesel production in Bangladesh. Procedia Engineering 90, 746-752 (2014).

25) Saravanana, S.; Nagarajan, G. Comparison of influencing factors of diesel with crude rice bran oil methyl ester in multi response optimization of NOx emission. Ain Shams Engine. J. 5, 1241-1248(2014).

26) Gul, K.; Yousuf, B.; Singha, A.; Singh, P.; Wani, A. Rice bran: Nutritional values and its emerging potential for development of functional food-A review. Bioact. Carbohydr. Dietary Fibre 6, 24-30 (2015).

27) Sakunpak, A.; Suksaeree, J.; Monton, C.; Pathompak, P.; Kraisintu, K. Quantitative analysis of $\gamma$-oryzanol content in cold pressed rice bran oil by TLC-image analysis method. Asian Pac. J. Trop. Biomed. 4, 119$123(2014)$.

28) Jesusa, S.P.; Grimaldib, R.; Hensea, H. Recovery of $\gamma$-oryzanol from rice bran oil by product using super critical fluid extraction. J. Supercrit. Fluids 55, 149$155(2010)$.

29) Joao, P.; Evangelista, A.; Chellappaa, T.; Coriolano, A.; Fernandes, V.; Souza, L.D.; Araujoa, A. Synthesis of alumina impregnated with potassium iodide catalyst for biodiesel production from rice bran oil. Fuel Process. Technol. 104, 90-95(2012).

30) Azmana, N.; Abdesha, P.; Al-Shorgani, N.; Hamid, N.; Kalil, M.; Bio hydrogen production from de-oiled rice bran as sustainable feed stock in fermentative process. Int. J. Hydrog. Energy 41, 145-156 (2016) . 